\title{
A Comparison of Embedded and Nonembedded Print Coverage of the U.S. Invasion and Occupation of Iraq
}

\author{
Michel M. Haigh, Michael Pfau, Jamie Danesi, Robert Tallmon, \\ Tracy Bunko, Shannon Nyberg, Bertha Thompson, Chance Babin, \\ Sal Cardella, Michael Mink, and Brian Temple
}

\begin{abstract}
This study examines the impact of embedded versus nonembedded (unilateral) news coverage during the U.S. invasion and occupation of Iraq. A content analysis was conducted of the Washington Post, New York Times, Los Angeles Times, and Chicago Tribune news coverage of the invasion and occupation examining whether embedded and nonembedded new reports were different and, if so, how. News reports were examined for differences in tone toward the military, trust in the military, framing, and authoritativeness. The results of the study revealed significant differences in overall tone toward the military, trust in military personnel, framing, and authoritativeness between embedded and nonembedded articles.
\end{abstract}

Keywords: embedded; nonembedded; print media coverage; war in Iraq

The history of the relationship between the press and the military dates back to the Civil War but became significantly strained during the Vietnam War. During Vietnam, reporters were given more access to the war due to television. However, the press and the military had differing goals. The military and the administration painted an optimistic picture of the war whereas the press sought to tell the whole story, which often contradicted official accounts (Paul and Kim 2004). During the Gulf War, a press pool was used, but these reporters had no eyewitness accounts of the events while they were happening (Brightman 2003). The military strived to improve access for the press, while attempting to ensure

Press/Politics 11(2):139-153

DOI: $10.1177 / 1081180 X 05286041$

(C) 2006 by the President and the Fellows of Harvard College 
the safety of journalists and the security of the mission being carried out (Paul and Kim 2004).

The relationship between the press and the military continues to evolve. During Operation Iraqi Freedom (OIF), more than six hundred U.S. and foreign journalists reported from aircraft carriers, Special Forces units, infantry, and Marine divisions (McLane 2004). Before the U.S.-led effort, journalists had never worked alongside the military to provide the public with a firsthand, virtually real-time account of combat operations (Knickmeyer 2003). The embedding program was directed by Victoria Clarke, who defined the process as "living, eating, moving in combat with the unit that [the journalist is] attached to" (Department of Defense [DoD] News Transcript 2003: 2). More than twentytwo hundred reporters and camera crews covered the war in Iraq. More than fourteen hundred of those reporters were unilaterals (nonembedded).

Despite the limitations of traveling with one unit, most journalists felt they had the access they needed. "Those most comfortable with the system tended to argue they had total freedom to cover 'virtually everything we wanted to cover' " (Miller 2004: 90). Bryan Whitman, then the assistant secretary of defense for public affairs admitted that embedding had a cost and that that cost was a narrow view of what is going on. One reporter stated that the articles being produced by print reporters were reports about "whatever piece of dirt you are sitting on" (Carr 2003: 3). These reports were discrete slices of information about what was happening in the war. By contrast, people received a deep, rich coverage of what is happening in a particular unit from embedded reporters (DoD News Transcript 2003).

This study examines how media embedding affected print news coverage of the war in Iraq. Specifically, the study compares the coverage of embedded and nonembedded journalists during the first twenty-one days of the U.S. invasion and twenty-one days of U.S. occupation of Iraq. Previous research by Pfau et al. (2004) compared the differences in newspaper coverage between embedded and nonembedded reporters during the first five days of OIF and operations Desert Storm and Enduring Freedom. They found embedded journalists covered conflicts in a more positive way than their nonembedded counterparts. There was no difference in the tone of coverage among the three conflicts studied.

Pfau et al. (forthcoming) built on their 2004 study by examining the impact of embedding on the tone and structure of television news coverage of OIF. They found that television stories filed by embedded reporters were more favorable toward the U.S. military and conveyed greater trust in U.S. military personnel than those filed by nonembedded reporters. They also found that television news reports from embedded journalists featured more episodic frames and that the tone of coverage of news frames differed between the invasion and occupation phases of the war. 
The current investigation builds on these studies by examining the effects of embedding on newspaper coverage. This study posits that the differences in tone and framing found in television news will also be found for print stories. It expands on past research (Pfau et al. 2004, forthcoming) by examining the impact of embedding on the tone of newspaper coverage, trustworthiness of military personnel, and framing and authoritativeness of news reports.

\section{Military-Media Relations}

The U.S. military and the media have had a long - and sometimes contentious - relationship. But as Paul and Kim (2004: 35) state, "Commonalities in the areas of professionalism and a commitment to public service allow for the possibility of cooperation.” For as long as the U.S. military has fought wars, the media have been covering them. No one is sure why there was a strained relationship between the press and military after the Vietnam War, but some argue it was due to the absence of military victory. During this conflict, the media were allowed unprecedented access because of the growth of television. But the military and the press had different goals of news coverage. As public support for the war declined, relations became even more strained (Paul and Kim 2004). After this, the military "learned the value of keeping the media controlled during the opening days of the engagement and becoming the main (if not the only) source of information during the times of war" (Paul and Kim 2004: 38).

During the operation in Grenada, the military contested the press's presence: for the sake of the operation's security, no press could be present during the invasion; therefore, no harm would come to journalists. The press was not provided free access until five days into the operation. By this time, though, the fighting was over. This led to accusations about violating the First Amendment (Paul and Kim 2004).

In Panama, a press pool was used, but this did not work due to logistical errors. It led to then-Chief of Staff Colin Powell issuing a memo urging the commanders to plan media coverage and media pool requirements at the same time combat operations were planned (Paul and Kim 2004).

During the Somalia operations in 1992, the press took control of their own operations. Because the Somalia operations were not "war operations," the press took the opportunity to take up posts within military theaters. The Pentagon did not implement the press pool, so the media had plenty of time to plan their own operations. This same process was also used in Haiti in 1994, except in that case the military maintained more control over press access. The only difference was that the military and the press were more cooperative and the media coverage was beneficial and did not violate operational security (Paul and Kim 2004).

During Bosnia and Kosovo, the proto-embedded press system was used. "Embedding referred to a reporter being assigned to a unit, deploying with it, 
and living with it throughout a lengthy period of the operation" (Paul and Kim 2004: 48). In 2002, the military and the press met and came to an agreement on the embedding program implemented during OIF. Victoria Clarke is credited with developing it (Paul and Kim 2004).

The DoD recognized potential advantages of having reporters embedded with military units. According to Brian Whitman, then deputy assistant secretary of defense for public affairs (2003a), it was an opportunity to build relationships, build trust, and expand on the reporting and understanding of standard operating procedures. Furthermore, DoD wanted to counter misinformation that would be spread by Saddam Hussein's regime following a U.S.-led invasion of Iraq. As Whitman (2003b) stated, "So one of the ways that you mitigate [the misinformation and disinformation], we felt, was that you put trained, objective observers on the battlefield to witness what's going on, and I think most reporters would consider themselves trained, and technical observers."

The other reason DoD wanted to use embedded media was to showcase U.S. service members to the American public. According to Whitman, "We also believed Americans deserved to see exactly how well trained their military forces were, how dedicated and professional" (in Purdum and Rutenberg 2003: B3).

The DoD first implemented the new embedding program with Operation Anaconda in Afghanistan in 2002 and then with OIF in 2003. Embedding allows reporters unfettered access to combat operations and the opportunity to experience war much the same way that service members do. In addition to the embedded reporters, nonembedded (or unilateral) reporters also covered operations in Iraq. Unilateral reporters had varying degrees of attachment to the units they covered. Some traveled with units and had the same access to operations and military personnel as the embedded reporters, while some traveled independently of the military.

\section{Literature Review}

As stated previously, this study seeks to build on previous research (Pfau et al. 2004, forthcoming) about the impact of embedding on news coverage of U.S. military operations. Living, eating, sleeping, and traveling with a unit leads to the development of interpersonal relationships. This can be explained best by a print journalist who stated, "I am a human being first and a journalist second" (Carr 2003: B2). There were several reports of reporters allowing military members to use their satellite phones to call home and inform family members that they were not hurt. Some reporters provided life-saving gear and also helped out when the units came under fire (Brightman 2003; Carr 2003). These interpersonal relationships are expected to impact the tone and framing techniques used in news stories. 


\section{Embedding Relationships}

A reporter's knowing the troops he or she covers can lead to bias. Embedded journalists are dependent on troops for food, transportation, and physical protection. Social penetration theory offers an explanation for this process. Social penetration theory explains "the range of interpersonal behaviors that occur in growing interpersonal relationships. These behaviors can be quantified in terms of amount of information exchange (breadth), intimacy level of information exchange (depth), and amount of time spent talking" (Taylor and Altman 1975: 18). The theory has often been analogized to peeling back the layers of an onion to expose more intimate layers of a subject.

Taylor and Altman (1987) identified four stages of relationships; the first is orientation, which occurs at the beginning of relationships when people are first getting to know each other. The second stage is exploratory affective exchange, where relationship partners reveal more details about aspects of their personalities that they guarded at the earlier orientation stage. The third stage is the affective exchange. "Interaction at outer layers of personality is open, and there is heightened activity at intermediate layers of personality ... generally there is little resistance to open explorations of intimacy" (p. 259). The fourth stage of relationship development is stable exchange, which "is characterized by continuous openness, as well as richness across all layers of personality” (p. 259).

These four stages happen over time. However, Soeters (2000) maintains the process is accelerated when military units engage in combat operations. Taylor (1979) explains that close contact with another makes self-disclosure more constant and that this leads to more liking. The accelerated social penetration process usually leads to greater levels of trust (Wheelus and Grotz 1977). When uncertainty levels are high (such as in times of war) and the circumstances are dangerous, accelerated trust bonds are formed (Meyerson et al. 1995); this "swift trust" bond can alter a person's judgment (Hensley 1996).

More recently, social penetration theory has been used in studies examining the U.S. military's use of embedded journalists in OIF (Pfau et al. 2004, forthcoming). Pfau et al. (forthcoming) speculated that the social penetration process would be accelerated for the journalists and members of the military units due to the strenuous combat situation in which the units operated. This accelerated relationship development was presumed to lead the reporters to produce news coverage that was more favorable toward the military than coverage produced by nonembedded journalists (Pfau et al. 2004).

This study seeks to replicate the study of embedded television news reports, but in the context of newspaper reports. Based on previous findings, it is expected that embedded newspaper reporters produced coverage that revealed a more positive tone toward the U.S. military than nonembedded newspaper reporters. 
Hypothesis 1: Compared to nonembedded (unilateral) coverage, embedded newspaper reports of combat operations (1) are more positive about the military as a whole and (2) imply greater trust toward military personnel.

\section{Framing}

Previous research has examined the differences in framing manifested in embedded versus nonembedded news reports. This study also adopts the assumption that embedded reporters will use more episodic frames than nonembedded reporters. Kosicki (2003) posited framing as the way a journalist chooses to package a story. According to Iyengar (1991), the concept of framing refers to the subtle differences in the way a topic is presented, and the term framing effects refers to differences in the ways consumers interpret the topic based on how it was framed. Entman (1993) stated that frames "call attention to some aspects of reality while obscuring other elements, which might lead audiences to have different reactions" (p. 55). Entman (1991) posited that frames lie within the structure of the news report. "Frames reside in the specific properties of the news narrative that encourage those perceiving and thinking about events to develop particular understandings of them. News frames are constructed from and embodied in the key words, metaphors, concepts, symbols, and visual images emphasized in a news narrative" (p. 7). Frames, in turn, will impact the way news reports are interpreted by media consumers (Pan and Kosicki 1993; Price and Tewksbury 1997).

Iyengar (1991) posited two types of framing - episodic and thematic. The episodic news frame on television takes the form of a case study or event-oriented report and depicts public issues in terms of concrete instances. Episodic reports present on-the-scene coverage of hard news and are often visually compelling. Because most television news is framed in an episodic way, people attribute the responsibility to individuals instead of to society (Iyengar 1991). Thematic frame places public issues in some more general or abstract context and the form of a "takeout," or "backgrounder," report directed at general outcomes or conditions (Iyengar 1991).

In a recent study on the effects of embedding journalists in military units, Pfau et al. (2004) found that the embedding process resulted in episodic framing of news stories for print. Pfau et al. (forthcoming) added that embedding inherently produces episodic news reporting. This study will examine if the framing differences found in the occupation and invasion phases of Iraq in television coverage will also be apparent in newspaper coverage.

Hypothesis 2: Embedded reporters employ more episodic framing of their news stories than nonembedded reporters. 


\section{News Authoritativeness}

Most studies of authoritativeness or credibility focus on the source as a person: a celebrity endorsing a product or a speaker or television personality attempting to persuade an audience. One key aspect of source credibility is authoritativeness (or expertise) (Carlson 1995; Goldsmith et al. 2000). Goldsmith et al. (2000) stated, "In this context, credibility refers to the extent to which the source is perceived as possessing expertise relevant to the communication topic" (p. 43). When examining credibility of news reports, Armstrong and Nelson (2003) stated that the expertise or authoritativeness of the source of a report is translated into the expertise (and credibility) of the news report. "In these cases, individuals use source as a heuristic cue, transferring the credibility of the source onto the information as a whole" (p. 9).

Slater and Rouner (1996) also found that message quality (well written and well produced) influences perceptions about the message. Armstrong and Nelson (2003) explain that how the story is interpreted by readers depends on the story content and the sources used within the story. A media consumer will look toward the source used within the story to assess the credibility of the information. They transfer the source credibility to the whole news report. Carlson (1995) stated, "People generally accept sources only if they believe that the sources know the reality of which they speak (expertise) and that they are honest in telling us what they know (trustworthiness)" (p. 40).

Since embedded reporters are traveling with military units and experiencing events as they happen, they will be perceived as having a high degree of knowledge and expertise about military operations. This will enhance the authoritativeness of their news reports.

Hypothesis 3: Stories written by embedded reporters exhibit more authoritativeness than stories written by nonembedded reporters.

\section{Method}

\section{Sampling Method and Unit of Analysis}

A content analysis was conducted of four national newspapers during the first three weeks of the invasion phase of the war in Iraq and three weeks during the occupation phase of the war. The analysis featured a sample of 452 articles provided by the Los Angeles Times, Chicago Tribune, Washington Post, and New York Times about military operations. The Los Angeles Times because it is a prominent West Coast newspaper, the Washington Post because it is a prominent East Coast paper, the Chicago Tribune because of its influence in the Midwest, and the New York Times because of its national influence.

The dates chosen for the invasion phase were March 20 to April 9, 2003, and the occupation dates were November 1 to 21, 2004. The 2003 dates selected 
marked the beginning of the invasion into Iraq concluding with April 9, 2003, when journalists coined "The Fall of Baghdad," which was symbolized by the fall of the statue of Saddam Hussein and considered as the end of the invasion phase of the war. Since the invasion phase ran the course of twenty-one days, the same number of days was selected for the analysis of the occupation phase to provide an equivalent comparison between the invasion and occupation phases. The time frame used for the occupation/resistance phase was dictated by the number of embedded reporters in Iraq. The embedded numbers were obtained from the DoD. The number of embedded reporters dropped after the fall of Baghdad from seven hundred to twenty-three (Strupp 2003). The numbers had increased to ninety-six in early November during the battle of Fallujah (Strupp 2004).

The articles were chosen using the search term "war in Iraq" in the lead paragraph or headline. Full-text articles were retrieved from the Newsbank Full Text Newspaper database. After performing a preliminary search, it was decided to stratify the sample over the forty-two days of coverage due to the large number of articles acquired in the preliminary search. The purposive sample selected every third day from the time frame. This provided a total of twelve days of print coverage (six days of invasion and six days of occupation) with a sample of more than 400 articles $(N=452)$. The unit of analysis was each single news story about a person, unit, or event with a clear beginning, middle, and end, excluding about 100 editorials, opinion pages, or commentaries as well as nonnewswor thy items.

\section{Coder Training}

Six DoD public affairs personnel, who were all enrolled in the joint communication course at a Midwestern university, conducted the content analysis. A written coding instrument was developed to code the sample. Coding norms were established during a supervised training session. Eight percent of the sample was coded during the training phases by each of the two teams (one team coding invasion, another team coding occupation). Coders established a high degree of standardization during the training sessions, resulting in effective intercoder reliabilities of .87 and .93 (Rosenthal 1984, 1987)

\section{Variables Measured}

Independent variable. The independent variable featured in the investigation was news correspondent status, which was operationalized based on information provided about reporters as embedded, nonembedded, or unknown. An embedded reporter was defined in the literature as a media representative remaining with a unit on an extended basis (Secretary of Defense [SECDEF], 2003). Coders distinguished between embedded and nonembedded correspondents based on dateline information that was provided in the newspaper articles. In some instances, it was unclear whether the correspondents were embedded or nonembedded, in which case they were coded as unknown. 
Dependent variables. The investigation featured four dependent variables. Overall tone of coverage toward the military was assessed using a global attitude measure adapted from Burgoon et al. (1978). It consisted of six 7-interval semantic differential scales: good/bad, positive/negative, wise/foolish, valuable/worthless, favorable/unfavorable, and acceptable/unacceptable. The reliability of this measure was $\alpha=.98(N=452)$. Depiction of the trustworthiness of the military personnel covered in news reports was assessed using the Individualized Trust Scale (ITS), which was initially developed by Wheelus and Grotz (1977) based on four 5-interval semantic differential scales adapted to 7-interval scales for this investigation. Specific scale items included trusting/untrusting, candid/deceptive, sincere/insincere, and honest/dishonest. The reliability rating of the trustworthiness scale was $\alpha=.98(N=452)$.

The extent to which each story unit employed episodic framing was measured with a single seven-interval scale: thematic/episodic. The scale was used previously by Pfau et al. (2004). Iyengar (1991) acknowledged that most news stories embody both episodic and thematic frames, with one being more dominant. Iyengar stated the frames usually tilted in one direction or the other. As Pfau et al. (forthcoming) stated, "The degree of the "tilt" using a relative measure assessing the extent to which each news story embodied episodic or thematic framing."

Authoritativeness is the "extent to which the article was perceived as possessing expertise relevant to the communication topic and can be trusted to give an objective opinion on the subject" (Goldsmith et al. 2000: 43). Authoritativeness of the story was measured using the authoritativeness dimension of the Source Credibility Scale (SCS) introduced by McCroskey in 1966 and perfected by McCroskey et al. (1974). This scale was adapted to media as opposed to source. As previously stated, Slater and Rouner (1996) also found that message quality influenced perceptions about the message. Armstrong and Nelson (2003) stated interpretation of the story by readers depends on the story content and the sources used within the story. Therefore, this measure was deemed appropriate to use to gauge the authoritativeness of the story. The reliability was $\alpha=.98$ $(N=452)$. Scale items included unreliable/reliable, uninformed/informed, unqualified/qualified, unintelligent/intelligent, worthless/valuable, and inexpert/expert.

\section{Results}

This study sought to expand upon previous studies by examining the effects of embedding on newspaper coverage of the invasion and occupation of Iraq. This study examined if differences in tone and framing found in television news reports would also be found in print stories. It also expanded on past research (Pfau et al. 2004, forthcoming) by examining whether credibility of news 
reports change when a reporter is embedded. Specifically, this study examined the tone of newspaper coverage, trustworthiness of military personnel, framing, and authoritativeness of news reports.

\section{Reporter Status}

Hypotheses 1 through 3 addressed differences between embedded and nonembedded news reports. To assess these predictions, a $2 \times 2$ MANCOVA was computed for journalist status (embedded/nonembedded) and timeline (invasion/occupation) on the dependent variables of overall tone toward military, trust toward individual troops, episodic framing, and authoritativeness of news reports. A covariate, day of coverage, was employed to determine whether these differences were greater over time. The omnibus results indicated significant differences for the covariate of day of coverage, Wilks's $\lambda F(4,417)=4.32$, $p<.01, R^{2}=.04$. Subsequent univariate tests revealed significant differences on the dependent variables of overall tone of coverage, $F(1,420)=3.69, p<.05, \eta^{2}$ $=.01$; and authoritativeness, $F(1,420)=11.35, p<.001, \eta^{2}=.03$. The results indicated that coverage became more positive, but authoritativeness declined over time.

The omnibus MANCOVA also revealed significant results for the independent variable of journalist status, Wilks's $\lambda F(4,417)=10.67, p<.001, R^{2}=.09$. Univariate results for dependent variables will be examined below in the context of specific hypotheses.

Hypothesis 1 predicted that embedded newspaper news reports of combat operations are more positive about the military and convey greater trust toward military personnel than those of nonembedded reporters. Subsequent univariate tests supported Hypothesis 1. The results revealed that, compared to nonembedded reports, embedded newspaper news reports were more positive toward the military, $F(1,420)=16.37, p<.001, \eta^{2}=.04$; and conveyed greater trust toward military personnel, $F(1,420)=30.81, p<.001, \eta^{2}=.07$. These means are displayed in Table 1.

Hypothesis 2 posited that embedded newspaper news reports of combat operations would contain more episodic framing. The univariate test revealed a significant main effect for reporter status on episodic framing, $F(1,420)=$ $11.76, p<.01, \eta^{2}=.03$. As Table 1 illustrates, embedded news stories depicted more episodic frames, thus supporting Hypothesis 2.

Hypothesis 3 predicted that, compared to nonembedded coverage, embedded newspaper news reports manifest greater authoritativeness. The univariate test revealed a significant effect for authoritativeness, $F(1,420)=13.72, p<$ $.001, \eta^{2}=.02$. As Table 1 shows, embedded newspaper news reports were judged more authoritative than nonembedded reports, thus supporting Hypothesis 3. 
Table I

Tendencies in print news stories as a function of journalist status

\begin{tabular}{llc}
\hline & \multicolumn{2}{c}{ Journalist Status } \\
\cline { 2 - 3 } Dependent Variable & $\begin{array}{c}\text { Embedded } \\
(n=50)\end{array}$ & $\begin{array}{c}\text { Nonembedded } \\
(n=375)\end{array}$ \\
\hline Tone of coverage & & \\
$\quad$ Overall tone & $4.48(0.81)^{*}$ & $4.13(0.67)$ \\
$\quad$ Trust & $4.68(0.82) *$ & $4.15(0.65)$ \\
Authoritativeness & $5.24(0.54)^{*}$ & $4.76(0.63)$ \\
Framing (episodic) & $4.42(2.04)^{*}$ & $3.29(1.76)$ \\
\hline
\end{tabular}

Note: Tone of coverage was assessed using two scales: Overall tone of coverage was assessed using six 7-interval scales; trust conveyed toward the individual troops depicted in news reports was measured using four 7-interval scales. Higher scores indicated more positive depictions. Authoritativeness (credibility) was assessed using four 7-interval scales. Higher scores indicated greater authoritativeness. Framing was assessed using a single 7-interval scale that measured the article's placement on an episodic versus thematic continuum. Standard deviations appear in parentheses. *Significant compared to nonembedded reports at $p<.01$.

The omnibus results revealed no significant main effect between invasion and occupation phases and no significant interactions of reporter status and phase of the conflict.

\section{Discussion}

This study provided fur ther insight into the nature of newspaper reporting by journalists embedded with military units during combat operations. Specifically, the study examined the impact that embedding had on news reports about the war in Iraq, both differences in news stories reported during the initial invasion phase as well as those reported more than a year later during the occupation/ resistance phase.

Newspaper coverage by embedded reporters during the invasion and occupation were significantly more positive toward the military than those of nonembedded reporters. In addition, reports of combat operations from embedded reporters depicted more episodic frames and were judged to be more authoritative than those of nonembedded reporters.

The pattern of results supported the hypothesis that embedded news reports of combat operations are more positive about the military and convey greater trust toward military personnel. Embedded journalists almost certainly move more rapidly through the social penetration process with the members of their military unit because of the stressful combat situation they are placed in (Pfau 
et al. forthcoming). The study suggests that as these relationships progress and the journalists begin to identify with their units, the journalists feel a greater sense of camaraderie. Additionally, because of the situation, the journalist must trust and depend on the military for food, transportation, and protection. This trust seems to grow and carry over into the newspaper articles the journalists write.

These findings confirm previous research that examined the differences in newspaper coverage between embedded and nonembedded reporters during the first five days of the war in Iraq and found that embedded journalists covered the conflict in a more positive way than did their nonembedded counterparts (Pfau et al. 2004).

The results also supported the prediction that embedded newspaper news reports of combat operations contain more episode framing. Iyengar (1991) posits that thematic framing requires in-depth, interpretive analyses, which take longer to prepare and would be more susceptible to charges of journalistic bias. Embedded reporters seemed to be attempting to present a quick on-the-scene portrayal of the events they were covering in a combat zone. They may have been seeking to provide a more visually stimulating story of war, and they probably did not have the time to present more in-depth, interpretive analysis. Again, these findings support the research of Pfau et al. (2004) that the embedding process resulted in episodic framing of news stories for print.

The study also supported Hypotheses 3, which posited that embedded news reports manifest a greater use of authoritativeness both during the invasion and occupation phase of the conflict. As stated earlier, one key aspect of source credibility is the authoritativeness (or expertise) of the source of the message (Carlson 1995; Goldsmith et al. 2000). Stories coming from the heart of the action where the reporter can get a firsthand view of the events written about were judged to be more authoritative. The embedded reporters are perceived to have a high degree of knowledge and expertise about military operations.

\section{Limitations}

With any study, there are some limitations. The time between the publication of the articles coded and the analysis of the articles is one limitation. The dates chosen for the invasion phase were March 20 to April 9, 2003, more than two years ago. It is possible that the articles may have been viewed differently if they were analyzed during the heightened tensions of the time in which they were written.

Another limitation in this research was potential bias of the coders. The coders all worked for DoD and were trained in military public affairs. Because of their affiliation with the military, the coders' views may have been biased toward coverage of military and combat operations. The coders were not aware of the literature and hypotheses, but they still had a bias about the military, if not specific to the study's predictions. 
Failing to include photos in the study was an extremely noteworthy limitation. The full-text articles retrieved from the Newsbank Full Text Newspapers did not include the photos that ran with the articles. One benefit of having stories filed from the heat of the action is the ability to include photos of the events being described. The battlefield is something most people will never see firsthand, and seeing photos from the action may have elicited more emotion from the coders. Future research should include examining the photos that ran with the articles.

\section{References}

Armstrong, Corey L., and Michelle R. Nelson. 2003. "Conditional Characterizations: The Influence of Cognition and Personality and Gender Assessments of Official and Non-Official Newspaper Sources.” Paper presented at the Midwest Association for Public Opinion Research annual meeting, Chicago, November.

Brightman, Carol. 2003. "In Bed with the Pentagon." The Nation, Mar. 17:1-3.

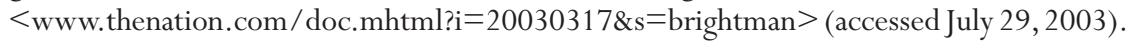

Burgoon, Michael, Marshall Cohen, Michael D. Miller, and Charles L. Montgomery. 1978. "An Empirical Test of a Model of Resistance to Persuasion." Human Communication Research 5:27-39.

Carlson, Earl R. 1995. "Evaluating the Credibility of Sources: A Missing Link in the Teaching of Critical Thinking." Teaching of Psychology 22(1):39-41.

Carr, David. 2003. "A Nation at War: The News Media.” New York Times, Mar. 31:B2.

Department of Defense [DoD] News Transcript. 2003. Deputy Assistant Secretary of Defense for Public Affairs Bryan Whitman interview with Dick Gordon of the Connection, NPR. (Also participating: Charles Lewis, Washington Bureau Chief for the Hearst Newspaper Chain; Eric Westervelt, correspondent for National Public Radio; and Chis Hedges, reporter for the New York Times.) March. DoD Defense News Transcripts via Defenselink: <http:// www.defenselink.mil/transcripts/2003/t03042003_t0304whitmannpr.html> (accessed November 28, 2004).

Entman, Robert. 1991. "Framing U.S. Coverage of International News: Contrasts in Narratives of the KAL and Iran Air Incidents." Journal of Communication 41(4):6-27.

Entman, Robert. 1993. "Framing: Toward Clarification of a Fractured Paradigm.” Journal of Communication 43:51-58.

Goldsmith, Ronald E., Barbara A. Lafferty, and Stephen J. Newell. 2000. “The Impact of Corporate Credibility and Celebrity Credibility on Consumer Reaction to Advertisements and Brands.” Journal of Advertising 29(3):43-54.

Hensley, Wayne E. 1996. "A Theory of the Valenced Other: The Intersection of the LookingGlass Self and Social Penetration." Social Behavior and Personality: An International Journal 24:293-308.

Iyengar, Shanto. 1991. Is Anyone Responsible? How Television Frames Political Issues. Chicago: University of Chicago Press.

Knickmeyer, Ellen. 2003. "Military Prepares to Take Journalists into War." NAPA News.com, Mar. 8:1-3. <www.napanews/com/templates/index.cfm?template=story_full\&id=45AEFCD3 -3675> (accessed July 29, 2003).

Kosicki, Gerald M. 2003. "The Media Priming Effect: News Media and Considerations Affecting Political Judgments.” In The Persuasion Handbook: Developments in Theory and Practice, ed. James Price Dillard and Michael Pfau, 63-81. Thousand Oaks, CA: Sage. 
McCroskey, James. 1966. "Scales for the Measurement of Ethos.” Speech Monographs 33:65-72.

McCroskey, James C., W. Holdbridge, and J. K. Toomb. 1974. "Instrument for Measuring Source Credibility of Basic Speech Communication Instructors.” Speech Teacher 23(1):26-33.

McLane, Brendan R. 2004. "Reporting from the Sandstorm: An Appraisal of Embedding." Parameters, Spring:77-88. <http://www.carlisle.army.mil/usawc/parameters/04spring/ mclane.htm $>$ (accessed July 28, 2003).

Meyerson, Debra, Karl Weick, and Roderick Kramer. 1995. "Swift Trust and Temporary Groups." In Trust in Organizations: Frontiers of Theory and Research, ed. Roderick M. Kramer and Tom R. Tyler, 166-95. Thousand Oaks, CA: Sage.

Miller, David, ed. 2004. Tell Me Lies, Propaganda, and Media Distortion in the Attack on Iraq. London: Pluto.

Pan, Zhongdang, and Gerald M. Kosicki. 1993. "Framing Analysis: An Approach to News Discourse." Political Communication 10:55-75.

Paul, Christopher, and James Kim. 2004. Reporters on the Battlefield: The Embedded Press System in Historical Context. Arlington, VA: Rand National Security Research Division, RAND Corporation.

Pfau, Michael, Michel M. Haigh, Mitchell Gettle, Michael Donnelly, Gregory Scott, Dana Warr, and Elaine Wittenberg. 2004. "Embedding Journalists in Military Combat Units: Impact on Newspaper Story Frames and Tone.” Journalism \& Mass Communication Quarterly 81(1):74-88.

Pfau, Michael, Michel M. Haigh, Lindsay Logsdon, Christopher Perrine, James P. Baldwin, Rick E. Breitenfeldt, Joel Cesar, Dawn Dearden, Greg Kuntz, Edward Montalvo, Dwaine Roberts, and Richard Romero. Forthcoming. "Embedded Reporting during the Invasion and Occupation of Iraq: How the Embedding of Journalists Affects Television News Reports.” Journal of Broadcasting \& Electronic Media.

Price, Vincent, and David Tewksbury. 1997. "News Values and Public Opinion: A Theoretical Account of Media Priming and Framing." In Progress in Communication Sciences, ed. George A. Barnett and Franklin J. Boster, 481-506. Norwood, NJ: Ablex.

Purdum, Todd S., and Jim Rutenberg. 2003. "A Nation at War: The News Media, Reporters Respond Eagerly to Pentagon Welcome Mat.” New York Times, Mar. 23:B3.

Rosenthal, Robert. 1984. Meta-Analytic Procedures for Social Research. Beverly Hills, CA: Sage.

Rosenthal, Robert. 1987. Judgment Studies: Design, Analysis, and Meta-Analysis. Cambridge: Cambridge University Press.

Secretary of Defense (SECDEF). 2003. Unclassified Message—Subject: Public Affairs Guidance on Embedding Media during Possible Future Operations/Deployments in the U.S. Central Command's Area of Responsibility. Feb. 10. Washington, D. C.: U.S. Department of Defense.

Slater, Michael D., and Donna Rouner. 1996. "How Message Evaluation and Source Attributes May Influence Credibility Assessment and Belief Change.” Journalism \& Mass Communication Quarterly 73(4):974-91.

Soeters, Joseph. 2000. “Culture and Uninformed Organizations.” In Handbook of Organizational Culture \& Climate, ed. Neal M. Ashkanay, Celeste Wilerom, and Mark Peterson, 465-81. Thousand Oaks, CA: Sage.

Strupp, Joe. 2003. “Only 23 Embedded Reporters Left in Iraq.” Editor \& Publisher, July 9. < http: / / editorandpublisher.com/eandp/news/article_display.jsp?vnu_content_id=193> (accessed September 28, 2004).

Strupp, Joe. 2004. “The Embeds Are Back, as Deadly Assault on Fallujah Looms.” Editor \& Publisher, Nov. 5. <http://editorandpublisher.com/eandp/news/article_display.jsp?vnu_content _id $=100>$ (accessed September 28, 2004).

Taylor, Dalmas. 1979. "Motional Bases.” In Self-Disclosure: Origins, Patterns, and Implications for Openness in Interpersonal Relationships, ed. Gordan J. Cheline and Associates, 110-50. San Francisco: Josey-Bass. 
Taylor, Dalmas, and Irwin Altman. 1975. "Self-Disclosure as a Function of Reward-Cost Outcome." Sociometry 38(1): 18 .

Taylor, Dalmas, and Irwin Altman. 1987. “Communication in Interpersonal Relationships: Social Penetration Processes.” In Interpersonal Processes: New Directions in Communication Research, ed. Michael E. Roloff and Gerald R. Miller, 257-77. Newbury Park, CA: Sage.

Wheelus, Lawrence R., and Janis Grotz. 1977. "The Measurement of Trust and Its Relationship to Self-Disclosure." Human Communication Research 3:250-57.

Whitman, Brian. 2003a. ASDPA Clarke Meeting with Bureau Chiefs. Transcript of the Department of Defense Media Briefing. January. Arlington, VA: U.S. Department of Defense.

Whitman, Brian. 2003b. Transcript of Deputy Assistant Secretary Whitman Interview with BBC TV. April. Arlington, VA: U.S. Department of Defense.

\section{Biographical Notes}

Michel M. Haigh (M.S., Texas Tech University, 2000) is a Ph.D. candidate in the Department of Communication at the University of Oklahoma.

Address: University of Oklahoma, 610 Elm Ave., Norman, OK 73019; phone: 405-325-3111; e-mail:mmhaigh@ou.edu.

Michael Pfau (Ph.D., University of Arizona) is a professor in and chair of the Department of Communication at the University of Oklahoma.

Jamie Danesi, Robert Tallmon, Tracy Bunko, Shannon Nyberg, Bertha Thompson, Chance Babin, Sal Cardella, Michael Mink, and Brian Temple were students in the Department of Defense Joint Course in Communication at the University of Oklahoma at the time this study was conducted. They are presently in military public affairs: Ms. Danesi, FORSCOM Public Affairs, Fort McPherson, GA; Major Tallmon, DINFOS, Fort Meade, MD; Captain Bunko, Langly Air Force Base, VA; Captain Nyberg, Air Force News, San Antonio, TX; Sergeant First Class Thompson, Ft. George G. Meade, MD; Technical Sergeant Babin, Naval Air Station Joint Reserve Base, New Orleans, LA; Gunnery Sergeant Cardella, Marine Corps Detachment B, Air Force News, Iwakuni, Japan; Staff Sergeant Mink, Marine Corps Base, Camp Lejeune, NC; Mr. Temple, U.S. Army Corp of Engineers, Europe. 